\title{
Consumption and Foraging Behaviors for Common Stimulants (Nicotine, Caffeine)
}

James G. Phillips, Jonathan Currie, and Rowan P. Ogeil

\section{QUERY SHEET}

This page lists questions we have about your paper. The numbers displayed at left can be found in the text of the paper for reference. In addition, please review your paper as a whole for correctness.

Q1. Au: Please provide author degrees.

Q2. Au: Please confirm author names appear correctly.

Q3. Au: Please provide complete author affiliations to include department, city, state, and country.

Q4. Au: Please confirm keywords appear correctly.

Q5. Au: Please limit abstract to 100 words per journal style. Please also confirm that the light edits that have been made to the abstract are acceptable.

Q6. Au: Can the highlights section either be removed or placed elsewhere in the paper? We typically like for the introduction to be the first section in the paper (after the abstract and keywords).

Q7. Au: Please provide correct/complete correspondence address as needed.

Q8. Au: Please spell out SE.

Q9. Au: Please spell out GPS.

Q10. Au: Please confirm Funding information appears correctly.

Q11. Au: For 20, please provide date website was accessed.

Q12. Au: For 25, please check page ranges used and correct accordingly.

Q13. Au: For 27, please check page ranges used and correct accordingly.

Q14. Au: For 56, please provide updated information, to include year and page ranges used, when available.

Q15. Au: For 59, please provide complete location of conference to include city and state.

\section{TABLE OF CONTENTS LISTING}

The table of contents for the journal will list your paper exactly as it appears below:

Consumption and Foraging Behaviors for Common Stimulants (Nicotine, Caffeine)

James G. Phillips, Jonathan Currie, and Rowan P. Ogeil 


\title{
Consumption and Foraging Behaviors for Common Stimulants (Nicotine, Caffeine)
}

\author{
James G. Phillips ${ }^{a}$, Jonathan Currie ${ }^{a}$, and Rowan P. Ogeil ${ }^{b}$ \\ ${ }^{\mathrm{a}}$ Auckland University of Technology, Auckland, New Zealand; ${ }^{\mathrm{b}}$ Eastern Health Clinical School, Monash University and Turning Point
}

Models are needed to understand the emerging capability to track consumers' movements. Therefore, we examined the use of legal and readily available stimulants that vary in their addictive potential (nicotine, caffeine). One hundred sixty-six participants answered the Kessler Psychological Distress Scale (K10), the Severity of Dependence Scale for nicotine and caffeine, and reported the number of times and locations stimulants were purchased and used. On average, nicotine dependent individuals made their purchases from 2 locations, while caffeine dependent individuals consumed caffeine at 2 locations, but some people exhibited a greater range and intensity of use. Stimulant foraging behavior could be described by power laws, and is exacerbated by dependency. The finding has implications for attempts to control substance use.

\section{Highlights}

- Stimulant foraging can be explained by power laws, and is greater in dependent users.

- Nicotine dependent individuals purchase nicotine from an average of two locations.

- Caffeine dependent individuals consume caffeine at an average of two locations.

\section{Introduction}

The use of psychoactive substances can lead to increased involvement, preoccupation with the substance, and dependence. ${ }^{1}$ Attempts to control the availability of psychoactive substances may be challenged by the increased appetitive behaviors of heavier users. $^{2}$ The tracking of patterns of substance use was only possible under specific circumstances, for example when documented by overdose. ${ }^{3}$ However, this 30 may change as emerging technologies (e.g., Google's "Your Timeline") have the potential to track and record people's purchases, ${ }^{4,5}$ or their locations. ${ }^{6,7}$ Hence, the present article sought methods of understanding the behavior of substance users, by consider35 ing the purchase and consumption of two legally available stimulants (nicotine and caffeine).
Nicotine is a widely used stimulant. ${ }^{8}$ Regular smoking is associated with dependence and long-term health problems, ${ }^{9}$ and restrictions are placed on nicotine use by specific groups (e.g., minors). In contrast, 40 few formal constraints are placed upon the use of caffeine. Caffeine is also used as a cognitive enhancer, but it has less addictive potential. ${ }^{10,11}$ Moderate consumption of caffeine is not associated with long-term adverse health effects. ${ }^{12}$ However, dosages and patterns of caffeine use have changed over the last 15-20 years, ${ }^{13}$ and a dependence syndrome has been documented. ${ }^{14}$ DSM5 indicates that caffeine warrants further study. ${ }^{15}$

\section{Simple central place foraging}

Studies of animal foraging behavior may offer convenient models to assist in the understanding of the ways in which substances might be acquired by users. ${ }^{16}$ The simplest (Central Place) model of foraging would propose that substance users commence their search for resources from a home base or some other familiar place. ${ }^{16}$ For example, there are relationships between the density of outlets licenced to sell alcohol, and engagement in risky patterns of alcohol consumption (e.g., "bingeing"), ${ }^{17}$ dependence, ${ }^{18}$ and increased levels of crime. ${ }^{19}$ If the locations where 
substances are available are fixed and known, then a substance user can systematically check them until the desired substance is obtained. In this case, the number linearly proportional to the number of locations at which a user purchases substances.

\section{Random brownian motion}

However, recent research has suggested that relation-

70 ships between spatial density of substance providers and harm are not linear in nature. These relationships depend on a variety of factors, such as individual drinking patterns and preferences, and social and structural characteristics such as access to transport. ${ }^{20}$

75 Where conditions are more uncertain, researchers have applied alternative models of foraging behavior. ${ }^{21,22}$ If resources are randomly available and access is influenced by a multiplicity of factors, foraging would likely involve a more random search pattern.

80 Random motions that have a probabilistic element are called Brownian motions. A search with a probabilistic element would fit the number of purchases and locations onto exponential functions that are linear on single log plots. ${ }^{21,23}$

85 However, there are other factors, such as dependence, that may also influence appetitive behaviors. ${ }^{1}$ Phillips and Ogeil ${ }^{24}$ asked people the numbers of times and places at which they consumed alcohol and gambled. People were asked about visits to a specific or problem drinkers were found to visit a specific venue more often, ${ }^{24}$ but problem drinkers and problem gamblers had an extended range, as they also reported that they visited other venues more often. ${ }^{24}$

\section{Lévy Walk}

Simulations and studies of animal foraging behavior suggest that random Brownian motion may suffice when resources are plentiful, but that other forms of search may become necessary if resources are 100 scarce. $^{23,25}$ Where resources are scarce, a form of foraging called a Lévy walk may be more efficient. During a Lévy walk foragers typically search within an area, but their movements are super-diffusive as they occasionally perform larger movements to extend their

105 range so that they no longer cover the same ground. ${ }^{26}$ In humans this has been likened to the decision as to whether to exploit "here" or explore "there." 27
However, these behaviors may not actually arise from conscious consideration as similar search patterns also occur in lower organisms. ${ }^{28}$ Simulations suggest that Lévy walk foraging tends to reduce periods of famine. ${ }^{29}$ As both resource availability and trip length have probabilistic elements, Lévy walk foraging would fit the numbers of purchases and locations onto power laws that are linear on double log plots. ${ }^{16,21,23}$

The foraging of substance users is relevant to: (1) governments and legislators who may wish to restrict access to a substance, ${ }^{30}$ and (2) the development of reminder technologies ${ }^{31-33}$ to provide outpatient support for people seeking to reduce the amounts that they drink or gamble. ${ }^{34}$ While previous studies have estimated visits to relatively fixed sites of consumption, ${ }^{24}$ it is also important to determine patterns of purchase and consumption occurring for more readily accessible products, such as nicotine and caffeine, that are associated with substance dependency.

To obtain an estimate of frequency of foraging, the present article uses the self-reported number of times and locations per day that consumption occurred, and examined the numbers of times and locations per week that purchases were made. Although these are not the raw frequencies of trips used by other researchers, ${ }^{23}$ the temporal contiguity of events can be used as an estimator of event frequency. ${ }^{35}$ Therefore, the consideration of times/locations per day/week would be homologous when converted into probability density functions. ${ }^{35}$ A comparison of two stimulants with varying addictive potential, and different constraints upon access will then provide insights into patterns of use and appropriate models explaining stimulant foraging (Simple Central Place, Random Brownian Motion, or Lévy Walks).

\section{Methods}

\section{Participants}

There were 166 participants (74 males, 92 females) with a mean age of 28.43 years (standard deviation 9.99 years). The majority of the sample (69.9\%) had some form of employment, and 51.2\% reported undertaking some form of study. Most participants had some level of post-secondary school education, with $14.5 \%$ having a trade or apprenticeship, and 57\% having an undergraduate or postgraduate university qualification. After reading an explanatory statement, participants completed an online survey approved by 
155 institutional ethics committees. The survey was available for 3 months. It was hosted on SurveyMonkey and posted on Australian (My Monash; Whirlpool Forum) and international (Reddit) online bulletin boards.

Participants were asked the typical number of times and places each: (1) day they used nicotine and caffeine; and (2) week they purchased nicotine and caffeine. Guidelines as to caffeine content were provided

165 to assist participants in estimating their daily dose of caffeine in milligrams. As the number of instruments devoted to caffeine is limited, the Severity of Dependence Scale (SDS) ${ }^{36}$ was adapted for use with caffeine (obtained Cronbach's alpha $=.83$ ). For comparison

170 purposes the same scale was used for nicotine (obtained Cronbach's alpha $=.94$ ). A cutoff of " 4 " on this scale is commonly used to separate "non-dependent" from "dependent" substance users. ${ }^{37,38}$ Only 12 respondents were dependent upon both caffeine and

175 nicotine. As an index of psychological distress, participants were also asked to complete the K10. ${ }^{39}$

\section{Results}

Participants that reported dependence upon nicotine

$(\mathrm{SDS}=7.08, \mathrm{SE}=.38)$ smoked significantly more times a day $\left(t(164)=11.574, p<.001, \eta^{2}=.45\right)$ than participants that were not dependent upon nicotine $(\mathrm{SDS}=.21, \mathrm{SE}=.06)$. Nicotine dependent individuals also smoked in significantly more places $(t(164)=$ 13.502, $p<.001, \eta^{2}=.53$ ) and purchased nicotine in

185 significantly more places $(t(164)=10.607, p<.001$, $\left.\eta^{2}=.41\right)$ at more times $\left(t(164)=12.995, \eta^{2}=.51\right.$; see Table 1). Nicotine dependence as measured by the SDS was associated with higher levels of psychological

Table 1. Mean number of times and places per day that a stimulant is used and the number of locations and times that a stimulant is purchased per week (standard errors in brackets).

\begin{tabular}{lllll}
\hline \multicolumn{3}{c}{ Nicotine } & \multicolumn{3}{c}{ Caffeine } \\
\hline Non-dept & Times used & Places used & Times used & Places used \\
& $.70(.27)$ & $.23(.07)$ & $2.41(.21)$ & $1.64(.09)$ \\
& Times bought & Places bought & Times bought & Places bought \\
& $.15(.04)$ & $.15(.05)$ & $1.66(.12)$ & $3.43(.32)$ \\
Dependent & Times used & Places used & Times used & Places used \\
& $11.87(1.35)^{\text {aa }}$ & $3.00(.28)^{\text {aa }}$ & $3.68(.28)^{\text {aa }}$ & $2.21(.12)^{\text {aa }}$ \\
& Times bought & Places bought & Times bought & Places bought \\
& $1.46(.12)^{\text {aa }}$ & $2.34(.30)^{\text {aa }}$ & $2.43(.31)^{\text {aa }}$ & $5.78(.90)^{\text {aa }}$ \\
\hline
\end{tabular}

${ }^{\mathrm{a}}$ Significantly different from non-dependent. distress as measured by the $\mathrm{K} 10(r(164)=.248, p<$ $.001)$.

Participants that reported a dependence upon caffeine (SDS $=6.24, \mathrm{SE}=0.32$ ) had a significantly $(t$ $\left.(164)=3.201, p<.01, \eta^{2}=.06\right)$ higher estimated dose of caffeine ( $405 \mathrm{mg} \mathrm{SE}=32$ ) than the estimated dose $(283 \mathrm{mg} \mathrm{SE}=21)$ of those that were not dependent upon caffeine (SDS $=0.98, \mathrm{SE}=0.09$ ). Caffeine dependent individuals reported consuming caffeine at significantly more times $\left(t(164)=2.805, p<.05, \eta^{2}\right.$ $=.07)$ and places $\left(t(164)=3.673, p<.001, \eta^{2}=.08\right)$ than those that were not caffeine dependent (see 200 Table 1). Caffeine dependent individuals purchased caffeine in significantly more places $(t(164)=3.096$, $\left.p<.01, \eta^{2}=.06\right)$ and more times $(t(164)=2,805, p$ $\left.<.01, \eta^{2}=.05\right)$. Caffeine dependence was associated with higher levels of psychological distress $(r(164)=205$ $.307, p<.001)$.

Simple, Brownian, and Lévy Walk models of foraging behavior were then applied to the patterns of foraging behavior, by testing whether the overall data were best fit by a linear, exponential function or power law. Whereas a simple linear model could explain between 12.6 and $73.5 \%$ of the variance, and an exponential model explained between 13.4 and $73.6 \%$ of the variance, a power law explained between 31.9 and $88.9 \%$ of the variance. Power laws always provided the best fit to spatio-temporal patterns of stimulant purchase and use.

Lines of best fit for power laws describing the times that stimulants were used (per day) or purchased (per week) may be see in Table 2. Although good fits were obtained for nicotine data, the better fit was obtained for daily use. Fits were not as good for the caffeine data, with the better fit occurring for caffeine weekly purchases.

To visualize foraging behavior Figure 1 presents scatter plots and lines of best fit for daily smoking and weekly caffeine purchases. Although the overall sample used nicotine on average about four times a day in around one location, some individuals demonstrated a greater range and intensity of use. The use of caffeine seemed somewhat more uniform. Again the overall sample exhibited somewhat restricted caffeine purchasing behavior (about two times per week from around four places) but there were still some individuals that demonstrated a greater range and intensity of purchasing.

To understand the foraging patterns of stimulant users, a power law was then fitted separately to 
Table 2. Lines of best fit for power laws describing use and purchase of stimulants (times and places are natural log transformed +1 ), for complete sample, dependent, and non-dependent stimulant users (Adjusted $r^{2}$ in brackets).

\begin{tabular}{lccc}
\hline & Complete Sample & Non-Dependent & Dependent \\
\hline Nicotine (daily use) & $Y=1.673 X+.026\left(R^{2}=.89\right)$ & $Y=1.593 X-.003\left(R^{2}=.90\right)$ & $Y=1.195 X+.739\left(R^{2}=.40\right)$ \\
Nicotine (weekly purchases) & $Y=.712 X+.051\left(R^{2}=.86\right)$ & $Y=.882 X+.015\left(R^{2}=.87\right)$ & $Y=.457 X+.369\left(R^{2}=.59\right)$ \\
Caffeine (daily use) & $Y=.350 X+.184\left(R^{2}=.32\right)$ & $Y=.339 X+.169\left(R^{2}=.32\right)$ & $Y=.185 X+.428\left(R^{2}=.06\right)$ \\
Caffeine (weekly purchases) & $Y=.505 X+.275\left(R^{2}=.66\right)$ & $Y=.505 X+.258\left(R^{2}=.64\right)$ & $Y=.485 X+.344\left(R^{2}=.65\right)$ \\
\hline
\end{tabular}

consumption patterns of the nicotine dependent and caffeine dependent individuals (see Table 2). For each group significant fits were obtained. The greater intercept for dependent stimulant users indicate a greater base rate of substance use. The shallower slopes for dependent stimulant users indicate that substance use and purchase are occurring over a greater range of locations.

\section{Discussion}

The present study examined common stimulants, and applied models of foraging behavior to their patterns of use. As frequency of consumption (or purchasing) increased, the range of locations where stimulants were consumed (or purchased) increased, but the best fit to these relationships was not linear. A power law best describes the foraging behavior of common stimulant users. For most individuals, stimulant use and purchase is limited to a couple of locations, but some individuals make appreciably greater access to stimulants over a wider number of locations. Such relationships are seemingly stronger for the stimulant with the greater addictive potential (nicotine). In addition, greater consumption over a larger range of locations. However, even dependent users of legally available stimulants seem to purchase these stimulants on average at a relatively limited number of times (i.e., nicotine) or consume them at a limited number of 265 locations (i.e., caffeine).

As a power law provides the better fit to data, this implies that Lévy Walks might better explain stimulant foraging behavior than Simple Central Place or Random Brownian motion. Even though much stimulant use might be close to a habitual location, some users demonstrate a greater range. The tendency to travel further, and/or access from more sources has implications for governments or legislators attempting to restrict access, ${ }^{40-42}$ as even one site providing substances to minors can increase purchasability and access in a neighbourhood. ${ }^{30}$ Not only are dependent substances users likely to pay more, ${ }^{2}$ the present data suggest that they probably access more locations as well, ${ }^{24}$ and this poses potential problems for attempts 280 to restrict access.

With increasing dependence upon a stimulant, the number of times or locations at which a stimulant is purchased or consumed increases, and similar patterns have been observed for alcohol. ${ }^{18}$ This might 285
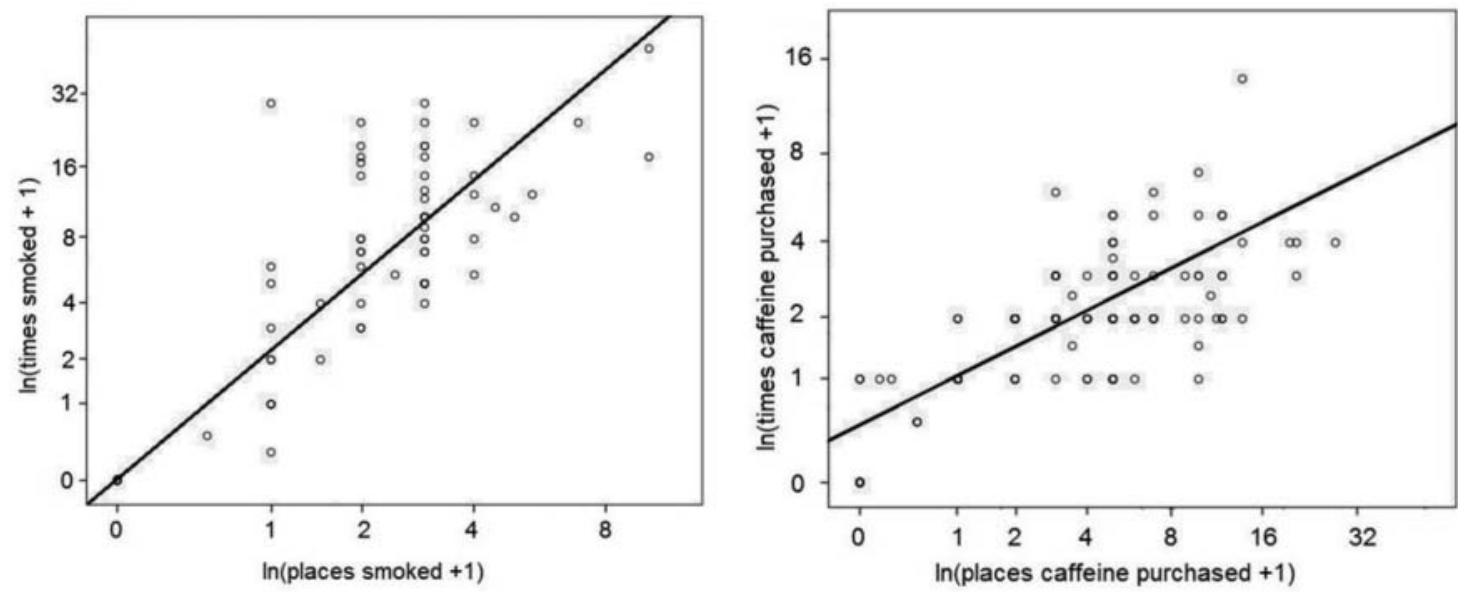

Figure 1. Scatter plots of best fitting power law for nicotine consumption per day, and best fitting power law for caffeine purchases per week. 
arise from: tolerance, destructive foraging, scarcity, or stimulant use. With increasing tolerance there is a need to increase the size and frequency of dosage, and this might contribute to the number of sites where stimulants are purchased. ${ }^{43}$ However, studies of foraging suggest that an organism might also increase its range because their behavior creates a scarcity of resources due to destructive foraging, ${ }^{26}$ exhausting a site's resources or in other ways preventing subse-

295 quent use. Conceivably the problem behaviors exhibited by gamblers or drinkers increase the likelihood that they be temporarily barred from a specific venue, but this is less likely for smokers or consumers of caffeine. Possibly greater consumption could lead to scar-

300 city. As dependent individuals consume more, they risk exhausting their supplies and are thus required to extend their range. ${ }^{22,44}$ Extending search patterns has been suggested to reduce the likelihood of scarcity or famine, ${ }^{29}$ but this seems unlikely for such readily

305 available stimulants. Indeed it is also possible that the use of stimulants may actually encourage a range of foraging behaviors, ${ }^{44}$ and there is experimental evidence to support such observations. ${ }^{43,45}$

\section{Implications}

310 These power laws provide a method of quantifying a cohorts' foraging behaviors that is sensitive to dependency and addictive potential. The power laws of dependent users exhibited: (1) higher intercepts, indicating greater consumption; (2) shallower slopes, indi-

315 cating that substance use occurs across a greater range of locations. Greater addictive potential seems to be associated with greater use per location. It is likely that dependent users of illegal stimulants would make a greater use of the more restricted number of sites 320 where purchases are available. Hence, greater intercepts and steeper slopes would be expected to any power laws applied to the foraging of those dependent on illegal stimulants.

The present data are relevant to the development of

325 technologies messaging clients and reminding them of their goal to reduce or abstain. ${ }^{33,34,46-48}$ Such technologies enable therapists to provide out-patient support, allowing interventions to be delivered "on site" in "real time,"

330 clients and reminding them as to their goal to reduce or abstain. The present data would be relevant to the development of interventions that might be more spatially and temporally contingent upon risk.

The movements of smart phone users can be estimated from their mobile phone calls. ${ }^{49}$ For each call, 335 the closest mobile phone tower can be used as an indicator of the phone user's location, hence resolution is a function of tower density. From such data, González et $\mathrm{al}^{49}$ noted that humans have a predictable range, typically spending the majority of their time in two 340 locations (e.g., home and work), with temporal periodicities corresponding to a 24 -hour cycle.

The present consideration of readily available substances offers insights as to the practical limits that might be required for systems that seek to provide outpatient support for dependent substance users. ${ }^{31-33}$ While there might be 306,695 tobacco outlets in the United States, ${ }^{50}$ given people's movements are relatively predictable, ${ }^{51,52}$ it could be feasible for apps to operate on the more limited number of venues and times that users and therapists can jointly nominate, and that might be more meaningfully associated with points of risk in their life space (e.g., Google's "Your Timeline"). Such subscription systems could message and interrupt users at times or locations when they indicate that they tend to be more vulnerable, and disrupt habitual behavior patterns. The greater range of locations frequented by dependent users would have implications for the upper limits required for such systems.

\section{Limitations}

Although an online survey was employed, online surveys may actually canvas a wider section of the community. ${ }^{53}$ Indeed, the methodology suggested is appropriate as it samples the population of technology users that would be likely to adopt such apps. ${ }^{54,55}$ Most substance users possess mobile phones, ${ }^{56}$ although there are indications that such populations may be concerned about their privacy. ${ }^{56,57}$

The present foraging data from stimulant users were consistent with power laws, ${ }^{58}$ and the use of daily frequencies actually acknowledges the periodicity of foraging behaviors. ${ }^{59}$ However, the use of daily frequencies may not be mathematically equivalent to outcomes obtained by raw frequency counts over an extended period, ${ }^{35}$ hence the author's recommend further study using GPS and improved methods of collecting self-reported use. ${ }^{33,55,60}$ 


\section{Conclusion}

380 Even though caffeine and nicotine are readily legally available, the foraging behavior of dependent users resembles that of organisms in circumstances of scarcity. Dependent stimulant users access stimulants more often and in more locations. Although the total

385 number of outlets for stimulants is quite high, the number of places a dependent user of stimulants actually frequents is potentially much less. However, some dependent users of stimulants appear to engage in a greater range and intensity of use than others, and

390 this may have implications for regulation and management.

\section{Funding}

Dr. Ogeil is the recipient of a Peter Doherty Early Career Fellowship from the National Health and Medical Research

\section{References}

1. Orford J. Addiction as excessive appetite. Addiction 2001; 96:15-31.

2. Manning WG, Blumberg L, Moulton LH. The demand for alcohol: the differential response to price. J Health Economics $1995 ; 14: 123-48$.

3. Forester MB. Temporal and geographic patterns in opioid abuse in Texas. J Addictive Diseases 2012; 31:93-9.

4. Hoffman DL, Novak TP, Peralta M. Building consumer trust online. Communications of the ACM 1999; 42:80-5.

5. Schafer JB, Konstan JA, Riedl J. E-commerce recommendation applications. Data Mining Knowledge Discovery 2001; 5:115-53.

6. Gravenhorst F, Muaremi A, Bardram J, Grünerbl A, May410 ora O, Wurzer G, Frost M, Osmani V, Arnrich B, Lukowicz P, Tröster G. Mobile phones as medical devices in mental disorder treatment: an overview. Pers Ubiquit Comput 2015; 19:335-53.

7. Montaner M, Lopez B, de la Rosa JL. A taxonomy of rec-

415 ommender agents on the internet. Artific Intelligence Rev 2003; 19:285-330.

8. Craig CR, Stitzel RE. Modern pharmacology with clinical applications. Philadelphia, PA: Lippincott Williams Wilkins, 2003.

9. U.S. Department of Health and Human Services. The Health Consequences of Smoking - 50 Years of Progress: A Report of the Surgeon General. Atlanta, GA: U.S. Department of Health and Human Services, Centers for Disease Control and Prevention, National Center for

10. Nehlig A. Are we dependent upon coffee and caffeine? A review on human and animal data. Neurosci Biobehav Rev 1999; 23:563-576.

11. Satel S. Is caffeine addictive?-a review of the literature. 430 The American Journal of Drug Alcohol Abuse 2006; 32:493-502.

12. Freedman ND, Park Y, Abnet CC, Hollenbeck AR, Sinha R. Association of coffee drinking with total and cause-specific mortality. New Eng J Med 2012; 366:1891-904.

13. Reissig CJ, Strain EC, Griffiths RR. Caffeinated energy drinks-a growing problem. Drug Alcohol Depend 2009; 99:1-10.

14. Juliano LM, Evatt DP, Richards BD, Griffiths RR. Characterization of individuals seeking treatment for caffeine dependence. Psychol Addict Behav 2012; 26:948-54.

15. Meredith SE, Juliano LM, Hughes JR, Griffiths RR. Caffeine use disorder: a comprehensive review and research agenda. J Caffeine Res 2013; 3:114-30.

16. Johnson SD. How do offenders choose where to offend? Perspectives from animal foraging. Legal Criminological Psychol 2014; 19:193-210.

17. Connor JL, Kypri K, Bell ML, Cousins K. Alcohol outlet density, levels of drinking, and alcohol-related harm in New Zealand: a national study. J Epidemiol Community Health 2011; 65(10):841-6.

18. Livingston M. Alcohol outlet density and harm: comparing the impacts on violence and chronic harms. Drug Alcohol Rev 2011; 30(5):515-23.

19. Day P, Breetzke G, Kingham S, Campbell M. Close proximity to alcohol outlets is associated with increased serious violent crime in New Zealand. Australian NZ J Public Health 2012; 36(1):48-54.

20. Cameron MP, Cochrane W, Gordon C, Livingston M. Alcohol outlet density and violence: a geographically weighted regression approach. Drug Alcohol Rev 2015; http://onlinelibrary.wiley.com/doi/10.1111/dar.12295/full

21. Buchanan $M$. The mathematical mirror to animal nature. Nature 2008; 453:714-6.

22. Bickell WK, Giordano LA, Badger GJ. Risk-sensitive foraging theory elucidates risky choices made by heroin addicts. Addiction 2004; 99:855-61.

23. Humphries NE, Queiroz N, Dyer JRM, Pade NG, Musyl MK, Schaefer KM, et al. Environmental context explains Lévy and Brownian movement patterns of marine predators. Nature 2010; 465:1066-9.

24. Phillips JG, Ogeil RP. Decisional styles and risk of problem drinking or gambling. Pers Individ Diff 2011; 51:521-6.

25. Bartumeus F, Catalan J, Fulco UL, Lyra ML, Viswanathan GM. Optimising the encounter rate in biological interactions: Lévy versus Brownian strategies. Physical Rev Let 2002; 88:097901.

26. Viswanathan GM, Buidyrev SV, Havlins S, da Luz, MGE, Raposo EP, Stanley HE. Optimising the success of random searches. Nature 1999; 401:911-4.

27. Volchenkov D, Helbach J, Tscherepanow M, Kuhnel S. Exploration exploitation trade-off features a saltatory search behaviour. J Royal Soc 2013; 10:20130352. Chronic Disease Prevention and Health Promotion, Office on Smoking and Health, 2014. 
28. Baronchelli A, Radicchi R. Lévy flights in human behaviour and cognition. Chaos Solitons Fractals 2013; 56:101-5.

29. Humphries NE, Sims DW. Optimal foraging strategies: Lévy walks balance searching and patch exploitation under a very broad range of conditions. J Theor Biol 2014; 358:179-93.

490 30. Forster JL, Murray DM, Wolfson M, Wagenaar AC. Commercial availability of alcohol to young people: results of alcohol purchase attempts. Preventive Medicine 1995, 24:342-7.

31. Auer M, Griffiths MD. Personalised feedback in the promotion of responsible gambling: a brief overview. Responsible Gamb Rev 2014; 1:27-36.

32. Heron KE, Smyth JM. Ecological momentary interventions: incorporating mobile technology into psychosocial and health behaviour treatments. Brit J Health Psychol $500 \quad 2010 ; 15: 1-39$.

33. Marsch LA. Leveraging technology to enhance addiction treatment and recovery. J Addictive Diseases 2012; 31:313-8.

34. Savic M, Best D, Rodda S, Lubman DI. Exploring the focus and experiences of smartphone applications for addiction recovery. J Addictive Diseases 2013; 32:310-9.

35. Ratcliff R. Group reaction time distributions and an analysis of distribution statistics. Psychol Bull 1979; 86:446-61.

36. Gossop M, Darke S, Griffiths P, Hando J, Powis B, Hall W, Strang J. The Severity of Dependence Scale (SDS): psycho-

510 metric properties of the SDS in English and Australian samples of heroin, cocaine, and amphetamine users. Addiction 1995; 90:605-14.

37. Martin G, Copeland J, Gates P, Gilmour S. The Severity of Dependence Scale (SDS) in an adolescent population of

515 cannabis users: reliability, validity, and diagnostic cut-off. Drug Alcohol Depend 2006; 83:90-3.

38. Topp L, Mattick RP. Choosing a cut-off on the Severity of Dependence Scale (SDS) for amphetamine users. Addiction 1997; 92:839-45.

520 39. Kessler RC, Andrews G, Colpe LJ, Hiripi E, Mroczek DK, Normand SL, Walters EE, Zaslavsky AM. Short screening scales to monitor population prevalences and trends in nonspecific psychological distress. Psychol Med 2002; 32:959-6.

40. Campbell CA, Hahn RA, Elder R, Brewer R, Chattopadhyay S, Fielding J, Naimi TS, Toomey T, Lawrence B, Middleton JC. The effectiveness of limiting alcohol outlet density as a means of reducing excessive alcohol consumption and alcohol-related harms. Am J Prev Med 2009; 37:556-69.

41. Huckle T, Conway K, Casswell S, Pledger M. Evaluation of a regional community action intervention in New Zealand to improve age checks for young people purchasing alcohol. Health Prom Int 2005; 20(2):147-55.

42. Reynolds RI, Holder HD, Gruenewald PJ. Community prevention and alcohol retail access. Addiction 1997; 92 (Supp. 3):S261-72.

43. Li F, Cao WY, Li MB, Xu Y, Zhang JW, Zhang JY, Luo XG, Dai RP, Zhou XF, Li CQ. A simple method for detection of food foraging behavior in the rat: involvement of NMDA and dopamine receptors in the behavior. Neuroscience 2012; 205:73-80.
44. Rosse RB, Fay-McCarthy M, Collins JP, Alim TN, Deutsch SI. The relationship between cocaine-induced paranoia and compulsive foraging: a preliminary report. Addiction 1994; 89:1097-104.

45. Foltin RW. Effects of amphetamine, dexfenfluramine, diazepam, and other pharmacological and dietary manipulations on food "seeking" and "taking" behavior in nonhuman primates. Psychopharmacol 2001; 158:28-38.

46. Gainsbury S, Blaszczynski A. A systematic review of internet-based therapy for the treatment of addictions. Clin Psychol Rev 2011; 31:490-8.

47. Kong G, Ells DM, Camenga DR, Krishnan-Sarin S. Text messaging-based smoking cessation intervention: a narrative review. Addict Behav 2014; 39:907-17.

48. Litvin EB, Abrantes AM, Brown RA. Computer and mobile technology-based interventions for substance use disorders: an organising framework. Addict Behav 2013; 38:1747-56.

49. González MC, Hidalgo CA, Barabási AL. Understanding individual human mobility patterns. Nature 2008; 453:779-82.

50. Rodriguez D, Carlos HA, Adachi-Mejia AM, Berke EM, Sargent JD. Predictors of tobacco outlet density nationwide: a geographic analysis. Tobacco Control 2012; doi: 10.1136/tobaccocontrol-2011-050120

51. Song C, Qu Z, Blumm N, Barabási A-L. Limits of predictability in human mobility. Science 2010; 327:1018-21.

52. Kang C, Ma X, Tong D, Liu Y. Intra-urban human mobility patterns: an urban morphology perspective. Physica A 2012; 391:1702-17.

53. Gosling SD, Vazire S, Srivastava S, John OP. Should we trust web-based studies? A comparative analysis of six preconceptions about internet questionnaires. Am Psychol 2004; 59:93-104.

54. Campbell B, Caine K, Connelly K, Doub T, Bragg A. Cell phone ownership and use among mental health outpatients in the USA. Pers Ubiquit Comput 2015; 19:367-78.

55. Thayer RE, Hutchinson KE. Improving accuracy of adolescents' substance use reports via text messaging. Addiction 2012; 107:1015-6.

56. Milward J, Day E, Wadsworth E, Strang J, Lynskey M. (in press). Mobile phone ownership, usage, and readiness to use by patients in drug treatment. Drug Alcohol Depend; doi: 10.1016/j.drugalcdep.2014.11.001. (accessed on December 3, 2014).

57. Phillips JG, Sargeant J, Ogeil RP, Chow YW, Blaszczynski A. Self-reported gambling problems and digital traces. CyberPsych Behav Soc Network 2014; 17(12):742-8.

58. Clauset A, Shallizi CR, Newman MEJ. Power-law distributions in empirical data. SIAM Review 2009; 51:661-703.

59. Freeman MP, Watkins NW, Yonkei E, Crowcroft J. Rhythm and randomness in human contact. International Conference on Advances in Social Networks Analysis and Mining. Odense August 9-11, 2010.

60. Kuntsche E, Labhart F. The future is now-using personal cellphones to gather data on substance use and related factors. Addiction 2014; 109:1052-3. 